\title{
SIRT3 overexpression antagonizes high glucose accelerated cellular senescence in human diploid fibroblasts via the SIRT3-FOXO1 signaling pathway
}

\author{
Bin Zhang • Shaoyuan Cui • Xueyuan Bai • \\ Li Zhuo • Xuefeng Sun • Quan Hong • Bo Fu • \\ Jianzhong Wang $\cdot$ Xiangmei Chen $\cdot$ Guangyan Cai
}

Received: 12 April 2012 / Accepted: 18 February 2013 / Published online: 14 March 2013

(C) The Author(s) 2013. This article is published with open access at Springerlink.com

\begin{abstract}
Sirtuin 3 (SIRT3) is one of the seven mammalian sirtuins, which are homologs of the yeast Sir2 gene. SIRT3 is the only sirtuin reported to be associated with human life span. Many recent studies have indicated that
\end{abstract}

Bin Zhang and Shaoyuan Cui, these authors contributed equally to this work.

B. Zhang $\cdot$ S. Cui $\cdot$ X. Bai $\cdot$ X. Sun $\cdot$ Q. Hong $\cdot$ B. Fu $\cdot$

J. Wang $\cdot X$. Chen $(\bowtie) \cdot$ G. Cai $(\bowtie)$

State Key Laboratory of Kidney Diseases,

Department of Nephrology, Chinese PLA General Hospital

and Military Medical Postgraduate College,

Beijing, 100853, China

e-mail: xmchen301@126.com

e-mail: caiguangyan@sina.com

\section{B. Zhang}

e-mail: binzhang301@163.com

S. Cui

e-mail: cshaoyuan@hotmail.com

X. Bai

e-mail: xueyuan_bai@yahoo.com.cn

X. Sun

e-mail: xfssun@126.com

Q. Hong

e-mail: redhq@163.com

B. Fu

e-mail: fubo01@263.net

J. Wang

e-mail: wangjianzhong_ne@163.com
SIRT3 levels are elevated by exercise and caloric restriction, but whether SIRT3 influences cell senescence under stressed conditions in human diploid fibroblasts has not been established. Our data showed that expression of

B. Zhang $\cdot$ X. Chen

School of Medicine, Nankai University,

Tianjin 300071, China

\section{B. Zhang}

Department of Nephrology,

The Second Affiliated Hospital,

Chongqing Medical University,

Chongqing 400010, China
L. Zhuo

Department of Nephrology,

China - Japan Friendship Hospital,

Beijing 100029, China

e-mail: belindazhl@yahoo.com.cn 
SIRT3 is elevated in human diploid fibroblasts under low glucose (3.3 mM glucose) growth conditions and decreased under high glucose (25 mM glucose) growth conditions. We have demonstrated that SIRT3 interacts with forkhead box protein O1 (FOXO1). High glucose levels also increased aging phenotypes and FOXO1 acetylation level. We have demonstrated that overexpression of SIRT3 under high glucose conditions reduces FOXO1 acetylation, suggesting that deacetylation of FOXO1 by SIRT3 elevates the expression of the FOXO1 target genes, catalase, and manganese superoxide dismutase (MnSOD) while decreasing senescence phenotypes. We studied the effects of SIRT3 protein knockdown by shRNA under low glucose conditions. The data showed that shRNA-SIRT3 accelerated senescence phenotypes and acetylation of FOXO1; the expression level of catalase and MnSOD decreased compared with the control group. As a consequence, SIRT3 antagonized cellular senescence with the characteristic features of delayed SA- $\beta$-gal staining, senescence-associated heterochromatin foci (SAHF) formation, and $\mathrm{p} 16^{\mathrm{INK} 4 \mathrm{~A}}$ expression. These results demonstrate for the first time that SIRT3 overexpression antagonizes high glucose-induced cellular senescence in human diploid fibroblasts via the SIRT3-FOXO1 signaling pathway.

Keywords SIRT3 $\cdot \mathrm{FOXO} 1 \cdot$ Human diploid fibroblasts $\cdot$ High glucose $\cdot$ Cellular senescence

\section{Introduction}

The sirtuins (or Sir2-like proteins) are a conserved family of $\mathrm{NAD}^{+}$-dependent protein deacetylases which overexpression has been reported to extend life span in yeast, worms, and flies (Kenyon 2010). Accumulating evidence suggests that reversible protein acetylation, which was historically considered to be limited to histone proteins, may be a major regulatory mechanism that controls functions of nonhistone proteins. Seven mammalian homologs belonging to the family of Sir2 proteins (Sirt 1-7) have been identified. The challenge now is to explain how these proteins communicate to regulate cross talk between aging and onset and progression of age-related disorders (de Oliveira et al. 2010). SIRT1 and SIRT6 are localized to the nucleus; SIRT7 is localized to the nucleolus; sirtuin 3 (SIRT3), SIRT4, and SIRT5 are localized to the mitochondria; and SIRT2 is localized to the cytoplasm. They regulate a wide range of intracellular processes (Haigis and Guarente 2006). Among them, SIRT3 is unique because it is the only analog which increased expression has been found to be associated with extended life span in humans (Rose et al. 2003; Bellizzi et al. 2005).

SIRT3 is localized predominantly in mitochondria and is considered to be a mitochondrial stress sensor that can modulate activity of several mitochondrial proteins involved in metabolism and oxidative stress regulatory pathways (Ahn et al. 2008; Scher et al. 2007; Onyango et al. 2002; Shi et al. 2005; Yang et al. 2010; Kong et al. 2010). Several lines of evidence link SIRT3 to metabolism: caloric restriction activates SIRT3 expression in both white and brown adipose tissues. In addition, cold exposure upregulates SIRT3 expression in brown fat, whereas elevated climatic temperature reduces its expression (Shi et al. 2005). Ang II downregulates SIRT3 mRNA, and this effect is inhibited by an AT1 antagonist in cultured tubular epithelial cells (Benigni et al. 2009). However, the relationship between SIRT3 and cell senescence is yet unclear.

A conserved insulinlike signaling pathway exists in invertebrates and vertebrates. The constituents of this pathway act as second messengers, conveying signaling information from the insulin receptor (termed DAF-2 in Caenorhabditis elegans and inR in Drosophila melanogaster) to key downstream effectors including the forkhead transcription factors (FOXO) (DAF-16 in C. elegans and dFOXO in Drosophila) (Murphy 2006). The FOXO family in mammals consists of the evolutionally highly conserved forkhead transcription factors forkhead box protein O1 (FOXO1), FOXO3a, FOXO4, and FOXO6, which are mammalian orthologs of DAF-16 in C. elegans. DAF-16 is required for life span extension in C. elegans (Huang and Tindall 2007; Zanella et al. 2010; Yamaza et al. 2010; Giannakou et al. 2008). A recent series of studies has demonstrated that FOXO factors play important roles in inducing various downstream target genes, including regulators of metabolism, cell cycle, DNA repair, cell survival or apoptosis, and oxidative stress response (Furukawa-Hibi et al. 2005; Sedding 2008). The activity of FOXO factors is regulated by a sophisticated signaling network that integrates information from PI3K/Akt and stress-induced signaling pathways resulting in a specific pattern of post-translational modifications. The multiple posttranscriptional events regulated the activity of FOXO proteins including phosphorylation, ubiquitylation, and 
acetylation at three different levels: subcellular localization, stability, and transcriptional activity.

A series of recent studies in mammalian cells have indicated that the reversible acetylation of FOXO proteins by nuclear coactivators and corepressors provides another layer of regulation of nuclear FOXO transcriptional factors. Acetylation of FOXO proteins by acetylases such as CBP and p300 increases in response to oxidative stress (Brunet et al. 2004; Frescas et al. 2005; Kitamura et al. 2005). Acetyl-FOXO proteins accumulate in the nucleus and cytoplasm associate with Pml bodies, which hinder their activity (Kitamura et al. 2005). A recent study showed that the human Sir2 ortholog SIRT1 binds and deacetylates FOXO proteins at lysine residues that are acetylated by $\mathrm{CBP} / \mathrm{p} 300$ (Daitoku et al. 2004). However, the effect of FOXO acetylation-deacetylation on the transcription of target genes is not quite so straightforward. We considered that acetylation could interfere with FOXO binding to target DNA and thereby prevent FOXO-mediated transcription. A recent study demonstrated that SIRT3 blocked cardiac hypertrophy by activating the FOXO3a-dependent, antioxidant-encoding genes, catalase and manganese superoxide dismutase (MnSOD), thereby decreasing cellular levels of ROS (Sundaresan et al. 2009).

In this study, we aimed to determine the relationship between SIRT3 and the senescence of WI-38 cells under conditions of low glucose $(40 \%$ below the normal serum glucose; lower concentration glucose, $3.3 \mathrm{mM}$ ), normal serum glucose (normal concentration glucose, $5.6 \mathrm{mM}$ ), and high serum glucose (high concentration glucose, $25 \mathrm{mM}$ ). Our results indicated that SIRT3 is significantly overexpressed in WI-38 cells under the low glucose condition compared with the other conditions. We have demonstrated that SIRT3 interacts with FOXO1. Furthermore, we found that nuclearacetylated FOXO1 is significantly increased in WI-38 cells under the high glucose vs. other conditions. Moreover, our data demonstrated that enhanced SIRT3 expression under high serum glucose activates the FOXO1-dependent antioxidant-encoding genes, catalase and MnSOD, and then antagonizes cellular senescence with the characteristic features of delayed SA- $\beta$ gal staining, senescence-associated heterochromatin foci (SAHF) formation, and p $16^{\mathrm{INK} 4 \mathrm{~A}}$ expression. Finally, we considered that SIRT3 delays the progression of human diploid fibroblast senescence via the SIRT3FOXO1 signaling pathway.

\section{Material and methods}

Materials

WI-38 cells (human embryonic lung diploid fibroblasts) and HEK 293 T cells (human embryonic kidney 293 T cells) were originally obtained from the American Type Culture Collection (Manassas, VA, USA). Dulbecco's Modified Eagle's Medium (11966025, 31600-034, 12100-046), fetal calf serum (FBS), and MitoTracker Green FM (M-7514) were purchased from Invitrogen (Carlsbad, CA, USA). TOMM20 antibody (ab56783), MnSOD antibody (ab86087), TATA-binding protein antibody (TBP ab818), FOXO1 antibody (ab70382), and p16 $6^{\mathrm{INK} 4 \mathrm{~A}}$ antibody (ab54210) were purchased from Abcam PLC (Cambridge, MA, USA). Catalase antibody (sc50508), SIRT3 antibody (sc-99143, sc-365175), FOXO1 antibody (sc-9809, sc-67140), and AcFOXO1 antibody (sc-49437) were purchased from Santa Cruz Biotechnology, Inc. (Santa Cruz, CA, USA). $\beta$-Actin antibody (A-1978) was purchased from Sigma-Aldrich (St. Louis, MO, USA). SIRT3 antibody (5490 s), Myc antibody (2278 s), FLAG antibody (2908 s), and normal rabbit IgG (2729) were purchased from Cell Signaling Technology, Inc. (Beverly, MA, USA). Anti-rabbit (A0208) or antimouse (A0216) IgG, horseradish peroxidase-linked species-specific antibodies, Cy3-labeled goat antirabbit $\operatorname{IgG}(\mathrm{H}+\mathrm{L})(\mathrm{A} 0516)$, fluorescein isothiocyanate (FITC)-labeled goat anti-rabbit $\operatorname{IgG}(\mathrm{H}+\mathrm{L})$ (A0562), Cy3-labeled goat anti-mouse IgG $(\mathrm{H}+\mathrm{L})(\mathrm{A} 0521)$, and 4',6-diamidino-2-phenylindole (DAPI) (C1002) were purchased from Beyotime (Beijing, China). FITCconjugated AffiniPure Rabbit Anti-Goat IgG $(\mathrm{H}+\mathrm{L})$ (ZF-0314) was purchased from ZSGB-Bio (Beijing, China).

pCMV6-AC-green fluorescent protein (GFP) tagged-ORF clone of Homo sapiens SIRT3 protein (pCMV6-AC-SIRT3-GFP, RG217770) and pCMV6Myc-DDK-tagged ORF clone of $H$. sapiens forkhead box protein O1 (FOXO1) protein (pCMV6-FOXO1Myc-DDK, RC200477) were purchased from OriGene (Rockville, MD, USA). pCMV6-AC-GFP vector was a kind gift from Chi-Dug Kang (Pusan National University). pGPU6-GFP-Neo-SIRT3-shRNA (A03390) and pGPU6-GFP-Neo-sh negative control (NC) (A03394) were purchased from Shanghai GenePharma (Shanghai, China). Nuclear-cytosol extraction kit 
(\#P1200) was purchased from Applygen Technologies Inc. (Beijing, China). Enhanced chemiluminescence detection reagents were purchased from Applygen Technologies Inc. (Beijing, China). jetPRIMETM transfection reagent was purchased from Polyplustransfection Inc. (Illkirch, France). SIRT3 fluorimetric drug discovery kit (AK557) was purchased from BML Inc. (Farmingdale, NY, USA). Coulter counter Z1 was from Beckman Coulter (Miami, FL, USA). All other chemicals were obtained from Sigma-Aldrich (St. Louis, MO, USA).

\section{Cell culture}

WI-38 cells and HEK 293 T cells were cultured in dulbecco's modified eagle medium (DMEM) supplemented with $10 \%$ FBS, $2 \mathrm{mM}$ glutamine, 100 $\mathrm{U} / \mathrm{ml}$ penicillin, and $100 \mu \mathrm{g} / \mathrm{ml}$ streptomycin glucose concentration in this medium was $5.6 \mathrm{mM}$. Cells were incubated at $37{ }^{\circ} \mathrm{C}$ in room air with $5 \%$ supplemental $\mathrm{CO}_{2}$ until reaching confluency. For experiments, cells were grown in $25-\mathrm{cm}^{2}$ flasks at an initial seeding density of $1 \times 10^{4} / \mathrm{cm}^{2}$ unless stated. Cells were passaged before reaching 70-80\% confluence. Viable cells were counted at each passage by trypan blue staining using a Coulter counter Z1 and population doublings (PDs) was determined as current PDs $=$ last PDs $+\log _{2}$ (collected cell number / seeded cell number) (Borradaile and Pickering 2009). Beginning with 20 PDs, WI-38 cells were passaged under three different growth conditions as follows: (1) low glucose, $40 \%$ below the normal glucose level (lower concentration glucose, $3.3 \mathrm{mM}, \mathrm{LG}$ ); (2) normal glucose (normal concentration glucose $5.6 \mathrm{mM}, \mathrm{NG}$ ); and (3) high glucose (high concentration glucose, $25 \mathrm{mM}, \mathrm{HG})$ media, respectively.

\section{Coimmunoprecipitation}

WI-38 cells were seeded at $75-\mathrm{cm}^{2}$ cell culture flasks. Harvested cells no less than $5 \times 10^{7} / \mathrm{ml}$ with triton lysis buffer $(20 \mathrm{mM}$ Tris-HCl, pH7.5, $0.12 \mathrm{M} \mathrm{NaCl}, 10 \%$ glycerol, $1 \%$ Triton X-100, $2 \mathrm{mM}$ ethylene diamine tetraacetic acid (EDTA), $1 \mathrm{mM}$ phenylmethanesulfonyl fluoride (PMSF), $10 \mu \mathrm{g} / \mathrm{mL}$ aprotinin, $1 \mathrm{mM} \mathrm{Na} \mathrm{VO}_{4}$ ). Lysed cells were centrifuged for $15 \mathrm{~min}$ at $12,000 \mathrm{rpm}$. The supernatant was precleared and incubated with FOXO1 antibodies overnight at $4{ }^{\circ} \mathrm{C}$ with gentle rotation and then protein A/G PLUS-agarose beads (Santa Cruz Biotechnology, Inc.), incubated for $1 \mathrm{~h}$ at $4{ }^{\circ} \mathrm{C}$ were added. Sepharose beads were washed three times with high salt lysis buffer ( $0.5 \mathrm{M} \mathrm{NaCl}, 1 \mathrm{mM}$ PMSF) and once with low salt lysis buffer $(0.12 \mathrm{M} \mathrm{NaCl}, 1 \mathrm{mM}$ PMSF). Beads were resuspended in $2 \times$ sodium salt (SDS) loading buffer, heated to $100{ }^{\circ} \mathrm{C}$ for $10 \mathrm{~min}$, and centrifuged for $1 \mathrm{~min}$ at 5,000 rpm. Supernatants were collected and then separated on a sodium dodecyl sulfate polyacrylamide gel electrophoresis (SDS-PAGE) followed by western blotting.

HEK 293 T cells were seeded at six-well plate. Transfection of expression for each SIRT3 each well was used for the NC and cotransfection of expression for SIRT3 and each FOXO1 well was used for the positive control. Lysed cells were centrifuged. The supernatant was incubated with Myc-tagged mAb-conjugated sepharose beads (Cell Signaling Technology, Inc.), the bound proteins were eluted and then separated on a SDSPAGE followed by western blotting.

Stable transfection of human diploid fibroblasts

pCMV6-AC-GFP vector, pCMV6-AC-SIRT3-GFP, pGPU6-GFP-Neo-shNC, and pGPU6-GFP-NeoSIRT3-shRNA were transfected into young WI-38 cells at 20 PDs with jetPRIMETM transfection reagent, according to the manufacturer's instructions. After $48 \mathrm{~h}$, the cells were selected by G418 $(300 \mu \mathrm{g} / \mathrm{ml})$. Colonies of stable transformations were isolated 2 weeks later and propagated in complete medium (colonies of pCMV6-AC-GFP vector and pCMV6-AC-SIRT3-GFP were cultured under high glucose media; colonies of pGPU6-GFP-Neo-shNC and pGPU6-GFP-NeoSIRT3-shRNA were cultured under low glucose media, containing $50 \mu \mathrm{g} / \mathrm{mlG} 418)$. The resulting transformations were termed pVector, pSIRT3, sh-NC, and shSIRT3, respectively.

Measurement of population doublings

Clones of transfected cells were obtained with G418 sustained selection. The PD number of a clone grown to about $10^{6}$ cells is about 20 . Therefore, the actual PD number of the transformants should be increased by 20 PDs when they are compared with the untransfected cells (Duan et al. 2001; Liu et al. 2010). When the cells stopped dividing and remained impossible to be further passaged for 2 weeks, they were regarded as growth arrested. Conclusions were confirmed by two independent transduction tests. 
Senescence-associated $\beta$-galactosidase staining

Assays were performed in standard plastic six-well dishes (Corning) containing subconfluent cultures of approximately 60,000 cells/well. Cells were washed thrice times in phosphate buffered saline (PBS), fixed for $10 \mathrm{~min}$ (room temperature) in $2 \%$ formaldehyde $/ 0.2 \%$ glutaraldehyde, washed again in PBS, and incubated for $12-16 \mathrm{~h}$ at $37{ }^{\circ} \mathrm{C}$ (without $\mathrm{CO}_{2}$ ) with $2 \mathrm{ml}$ fresh senescence-associated $\beta$-gal (SA- $\beta$-gal) stain solution (1 mg/ml X-gal, $40 \mathrm{mM}$ citric acid/sodium phosphate, $5 \mathrm{mM}$ potassium ferrocyanide, $5 \mathrm{mM}$ potassium ferrocyanide, $150 \mathrm{mM} \mathrm{Nacl}$, and $2 \mathrm{mM} \mathrm{Mgcl}_{2}$ [pH6.0]). Thereafter, cells were washed in PBS, and the number of $\beta$-galactosidase activity-positive cells (blue staining) was counted under a microscope.

Senescence-associated heterochromatin foci analysis

SAHF formation is a novel specific biomarker of cellular senescence because marked focal heterochromatin exists in aged cells. To determine SAHF formation, cells were cultured directly on glass cover slips and then fixed with $4 \%$ paraformaldehyde. After washing with PBS, cells were permeabilized with $0.2 \%$ Triton X-100/PBS for $10 \mathrm{~min}$. DNA was visualized by DAPI $(1 \mu \mathrm{g} / \mathrm{ml})$ for 1 min at room temperature and then washed with PBS three times. Cover slips were mounted in a $90 \%$ glycerol PBS solution. Cover slips were examined under a microscopy.

Preparation of whole-cell protein lysates and western blot analysis

WI-38 cells were homogenized by sonication and highspeed centrifugation. Cell lysate supernatant was assayed for total protein content and subjected to western blot analysis as described by Zhuo et al. (2009). Briefly, a total of $60 \mu \mathrm{g}$ protein was separated by $6-15 \%$ SDSPAGE and then transferred to a membrane that was then blocked with $2.5 \%$ casein solution, probed with a primary antibody at $4{ }^{\circ} \mathrm{C}$ or $28{ }^{\circ} \mathrm{C}$ overnight, and afterward incubated with a horseradish peroxidase-conjugated secondary antibody. The protein bands were visualized by enhanced chemiluminescence detection reagents.

Preparation of nuclear and cytosolic protein lysates

The cells were washed twice with ice-cold PBS buffer. Cytosol extraction buffer A was added. The lysate was then incubated on ice for $15 \mathrm{~min}$, and $5 \%$ cytosol extraction buffer $\mathrm{B}$ was added to the suspension, which was then centrifuged at $12,000 \times g$ at $4{ }^{\circ} \mathrm{C}$ for $5 \mathrm{~min}$. Supernatant was collected for cytosolic protein lysate. The remaining cell pellet was resuspended in nuclear extraction buffer. The suspension was incubated on ice for $30 \mathrm{~min}$ and then centrifuged at $12,000 \times g$ for $5 \mathrm{~min}$ at $4{ }^{\circ} \mathrm{C}$. The supernatant was collected for nuclear protein lysate. Nuclear and cytosolic protein concentrations were determined with a bicinchoninic acid (BCA) protein assay. Both nuclear and cytosolic lysates were used for subsequent western blotting experiments (described above).

In vitro Sirt3 deacetylation activity assay

Deacetylation was measured using the Fluor-de-Lys kit. The acetylated lysine residue was coupled to an aminomethylcoumarin moiety. The peptide was deacetylated by Sirt3, followed by the addition of a proteolytic developer that released the fluorescent aminomethylcoumarin. Briefly, enzyme preparations were incubated with $3 \mathrm{mM} \mathrm{NAD}^{+}$for $45 \mathrm{~min}$ at $37^{\circ} \mathrm{C}$ followed by incubation in developer for $15 \mathrm{~min}$ at $25^{\circ} \mathrm{C}$. Fluorescence was measured by excitation at $360 \mathrm{~nm}$ and emission at $460 \mathrm{~nm}$ and enzymatic activity was expressed in relative fluorescence units. Assays were performed in triplicate.

Immunofluorescence microscopy

To study the distribution and relative amounts of SIRT3, we performed immunofluorescent staining for SIRT3 in WI-38 cells using a routine procedure. Briefly, cells were incubated with $400 \mathrm{nM}$ MitoTracker Green FM for $40 \mathrm{~min}$ at $37^{\circ} \mathrm{C}$ in PBS. The unbound MitoTracker was removed by washing the cells three times with PBS for $15 \mathrm{~min}$ each. The cells were fixed in $4 \%$ paraformaldehyde for $30 \mathrm{~min}$, washed in PBS and then permeabilized with $0.2 \%$ Triton X-100 for 15 min, blocked with $1 \%$ bovine serum albumin in PBS for $1 \mathrm{~h}$, and incubated overnight with SIRT3 antibody (1:50) or TOMM20 antibody $(1: 100)$ overnight at $+4{ }^{\circ} \mathrm{C}$, FOXO1 antibody $(1: 50)$ at $4{ }^{\circ} \mathrm{C}$ in a moist chamber. After washing with PBS three times, the cells were incubated for $1.5 \mathrm{~h}$ with Cy3- or FITC-conjugated anti-IgG secondary antibody (1:400 or 1:50). After washing with PBS three times, nuclear staining was carried out with DAPI $(1 \mu \mathrm{g} / \mathrm{ml})$ for $1 \mathrm{~min}$ in PBS, 
and the cells were then washed with PBS three times. All microscopy and imaging analyses were done in the digital confocal microscopy core facility of the University of Chicago.

\section{Statistical analysis}

All data analyses were performed with SPSS ver. 17.0 (SPSS Inc., Chicago, IL, USA) software values are expressed as mean $\pm \mathrm{SD}$. Comparisons among groups were conducted with analysis of variance (ANOVA). In all analyses, $P<0.05$ denoted the presence of a statistically significant difference. All experiments were repeated at least three times.

\section{Results}

Population doublings of the WI-38 cells under three different growth conditions

We monitored the cellular proliferation and PDs during the entire cellular life span under LG, NG, and $\mathrm{HG}$ conditions. The WI-38 cells in the LG group displayed an increased life span (59 PDs), while the cells in the NG group showed a normal life span (52 PDs), but the cells in the HG group showed a shorter life span (45 PDs). Experiments were terminated when cells stopped proliferating and underwent replicative senescence. As indicated in Fig. 1, the life span of WI-38 cells grown in LG medium was extended by an additional 3 weeks accompanied by an additional seven PDs compared with the NG group. However, the life span of WI-38 cells grown in HG medium was decreased by 2 weeks accompanied by seven PDs compared with the NG group. In a culture cellular system, this study established that LG may provide an excellent in vitro model for caloric restriction (CR) studies. LG can induce longevity in WI-38 cells, but HG accelerated WI-38 cellular senescence.

Senescence phenotypes in WI-38 cells under three different growth conditions

The expression of neutral $\beta$-galactosidase activity has been demonstrated as a characteristic biomarker for senescent cells in culture and in vivo (Dimri et al. 1995). It has been reported that yeast cells grown on $0.5 \%$ glucose medium exhibited a longer life span than cells grown on $2 \%$ glucose medium (Lin et al. 2000). We discovered that the percentages of SA- $\beta$ gal positive cells were decreased significantly in the LG group compared with the $\mathrm{NG}$ and $\mathrm{HG}$ groups (Fig. 2a and b). These results suggest that low glucose reduces cellular replicative senescence in vitro.

The accumulation of SAHF is another specific biomarker of senescent cells (Narita et al. 2003). As shown in Fig. 4, senescence induced by HG conditions was characterized by pronounced punctuated DNA foci, which were visualized by DAPI staining. Moreover, high glucose leads to cell hypertrophy and nuclear volume increase.

The protein levels of $\mathrm{p} 16^{\mathrm{INK} 4 \mathrm{~A}}$ (another biomarker of cell senescence) (Lauri et al. 2001) expression in the $\mathrm{HG}$ group were significantly higher than in the LG and NG groups (Fig. 2c and d). We found that low glucose decreased $\mathrm{p} 16^{\mathrm{INK} 4 \mathrm{~A}}$ expression and thus promoted proliferation and longevity in WI-38 cells.

Differential expression of SIRT3 in WI-38 cells under three different growth conditions and SIRT3 interaction with FOXO1

It was reported that in mice, SIRT3 protein levels in the liver were decreased by a long-term high-fat diet (Bao et al. 2010) and that SIRT3 expression in white and brown fat was elevated by caloric restriction (Shi et al. 2005). We decided to investigate whether low glucose affects SIRT3 expression in human diploid fibroblasts in vitro. After culturing WI-38 cells from 20 to 35 PDs in low glucose, normal glucose, and high glucose media, SIRT3 protein levels increased significantly in the LG group compared with the NG and HG groups (Fig. 3a and b). Meanwhile, SIRT3 is the enzyme that catalyzes $\mathrm{NAD}^{+}$-dependent protein deacetylation. Our experimental data showed that the levels of SIRT3 activity were decreased in the HG group compared with the LG and NG groups (Fig. 3e). To obtain additional evidence for these findings, we carried out confocal microscopic analysis of cultured WI-38 cells stained for endogenous SIRT3. Mitochondria and nuclei were localized by MitoTracker or TOMM20 (green) and DAPI (blue) staining, respectively. We found that the endogenous SIRT3 was highly expressed in the mitochondria and cytoplasm (Fig. 4a and d), FOXO1 was expressed in the cytoplasm and nuclei (Fig. 4b and e), and the SIRT3 staining strongly overlapped with that of FOXO1 in the cytoplasm (Fig. 4c). These results indicated a hypothesis 


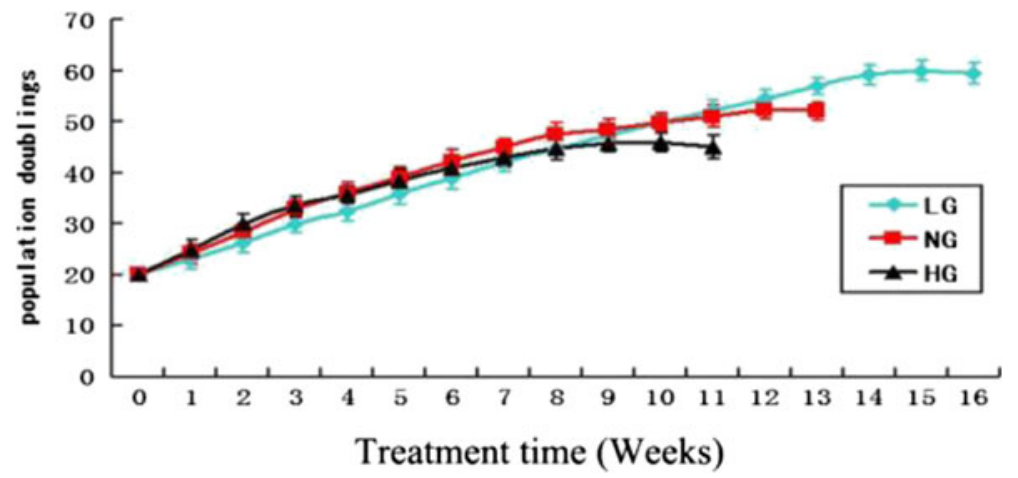

Fig. 1 Low glucose extends lifespan of WI-38 cells. PD curves of WI-38 cells in LG, NG, and HG growth conditions. Viable cells were counted at each passage by trypan blue staining using a

that there is a possible interaction between the SIRT3 protein and FOXO1 protein. SIRT3 may deacetylate FOXO1 in the cytoplasm. Furthermore, we carried out Co-IPs between SIRT3 and FOXO1. As is shown in Fig. 5, we could confirm that SIRT3 was binding with FOXO1. Overall, these data have demonstrated that SIRT3 protein physically interacts with FOXO1. In addition, the fluorescence intensity of SIRT3 and FOXO1 showed a marked increase in WI-38 cells in the LG group compared with the NG and HG groups. These results suggest that low glucose activates SIRT3

\section{a $n \mathrm{~d}$}

Fig. 2 Changes of

senescence-associated features in WI-38 cells under three different growth conditions. a WI-38 cells ( 35 PDs) grown under LG, NG, and $\mathrm{HG}$ incubation conditions were stained for SA- $\beta$ gal, which shows blue precipitation in the cytoplasm in senescent cells. b The percentage of SA- $\beta$-gal stained positive cells. For each group, 100 to 200 cells were counted. c, d Western blot analysis of $\mathrm{p} 16^{\mathrm{INK} 4 \mathrm{~A}}$ in the three groups. Comparison among groups was conducted with ANOVA. ${ }^{*} P<0.05$ vs. LG group, ${ }^{\#} P<0.05$ vs. NG group. Data represent three experiments with similar results. a $100 \times$
Coulter counter $\mathrm{Z1}$ and PDs were determined as current PDs=last PDs $+\log _{2}$ (collected cell number / seeded cell number). Each graph depicts the averaged results from three longevity assessments

FOXO1 expression in vitro. These results may be attributed to SIRT3, while being closely related to low glucose delaying cellular senescence.

FOXO1 transactivation activity in WI-38 cells under three different growth conditions

The FOXO transcription factors play a central role in regulating stress response (Sedding 2008; FurukawaHibi et al. 2005), and FOXO factors activate the expression of its target genes, such as catalase and MnSOD. In

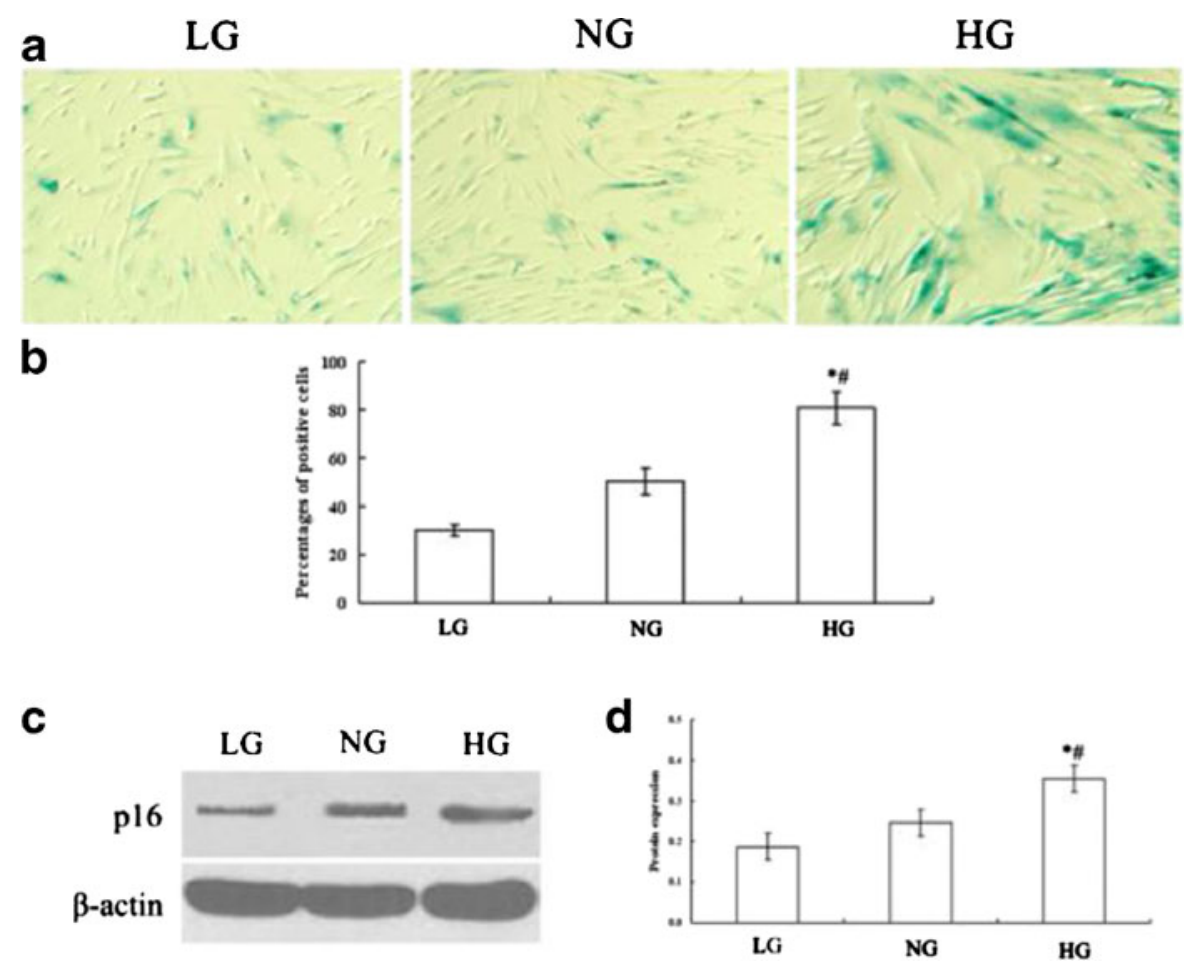




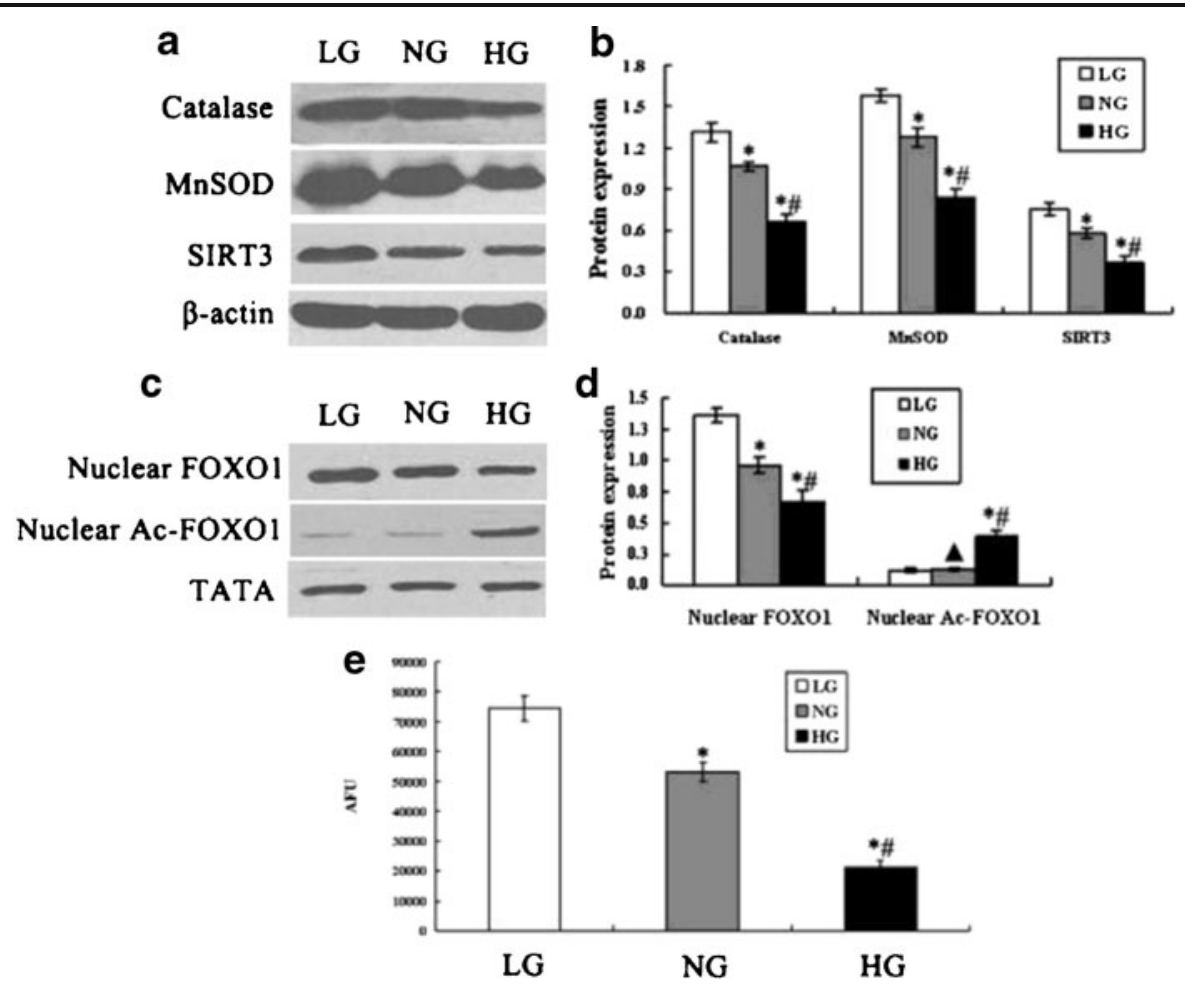

Fig. 3 Expression of SIRT3, catalase, MnSOD, nuclear FOXO1, and nuclear Ac-FOXO1 in WI-38 cells under three different growth conditions. a Western blot analysis of catalase, MnSOD, and SIRT3 in the LG group, NG group, and HG group. b Catalase, MnSOD, and SIRT3 were compared using ANOVA. ${ }^{*} P<0.05$ vs. LG group, ${ }^{\#} P<0.05$ vs. NG group. c Western blot analysis of nuclear FOXO1 and nuclear Ac-FOXO1 in the LG group, NG group, and HG group. d Nuclear FOXO1 and

mammalian cells, deacetylation of FOXO factors is a general mechanism that activates FOXO transcriptional activity (Daitoku et al. 2004; Brunet et al. 2004). To study the effect of FOXO acetylation state on target gene transcription, we tested the protein levels of nuclear FOXO1, and acetylated FOXO1 (Ac-FOXO1) and its target genes. As shown in Fig. 3c and d, the protein levels of nuclear total FOXO1 expression in the LG group were significantly higher than those in cells exposed to NG and $\mathrm{HG}$ conditions, but nuclear Ac-FOXO1 expression in the HG group was significantly higher than in the NG and HG groups. Nuclear deacetylated FOXO1 protein expression in the HG group was significantly lower than those in the other groups. We concluded that high serum glucose activates acetylation of FOXO1 and inhibits FOXO1 activity. In addition, catalase and MnSOD protein expressions of the LG group were significantly higher than in the other groups (Fig. 3a and b). nuclear Ac-FOXO1 were compared with ANOVA. ${ }^{*} P<0.05$ vs. LG group, ${ }^{\wedge} P>0.05$ vs. LG group, ${ }^{\#} P<0.05$ vs. NG group. e The deacetylase activity of Sirt3 in the LG group, NG group, and HG group. ${ }^{*} P<0.05$ vs. LG group, ${ }^{\#} P<0.05$ vs. NG group. $A F U$ arbitrary fluorescence units. Equal loading was confirmed by reprobing the blots for $\beta$-actin (cytosolic) or TATA-binding protein $(T B P)$ (nuclear). Data represent three experiments with similar results

SIRT3 overexpression upregulates FOXO1-targeted gene expression through its deacetylase activity

As SIRT3 is an NAD ${ }^{+}$-dependant deacetylase, we investigated whether SIRT3 affects FOXO1 acetylation. For this purpose, pSIRT3 and pVector were stably transfected into the WI- 38 cells at 20 PDs. A clone was grown to about 40 PDs under high glucose media. Western blot analysis was performed from $\mathrm{pSIRT} 3$ cells and revealed approximately 2.3-fold and 2.5-fold increases of total SIRT3 protein, respectively, compared with control and vector groups (Fig. 6a and b). SIRT3 overexpression keeps FOXO1 acetylation to a very low level (Fig. 6c and d). However, the protein levels of nuclear total FOXO1 expression of the three groups did not show a statistically significant difference (Fig. 6c and d). These results implicate SIRT3 as a positive cofactor for FOXO1-dependent transactivation through its deacetylase activity. At the 

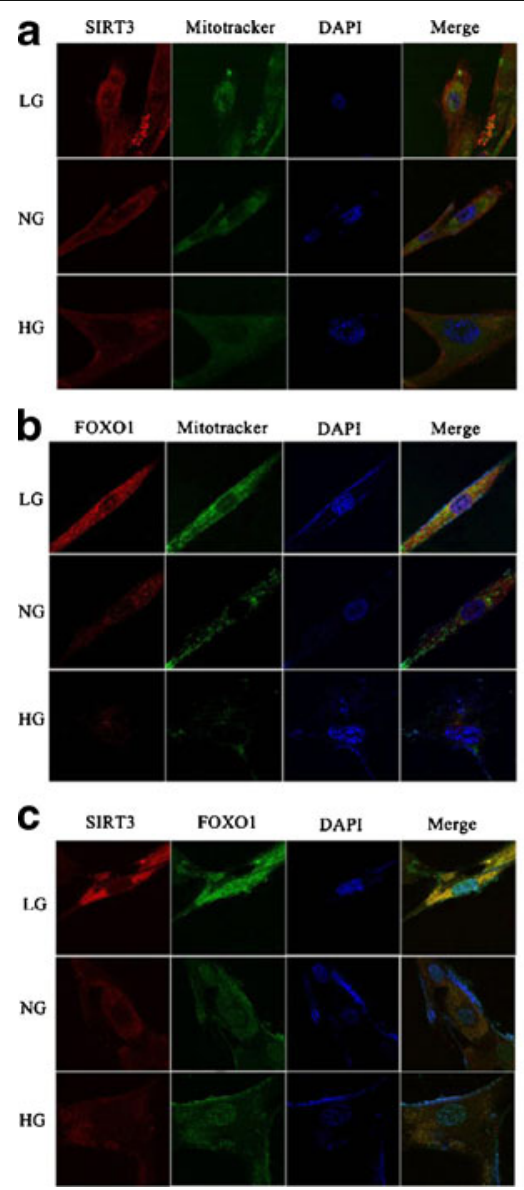

Fig. 4 Confocal microscopic images of SIRT3, mitochondria, and FOXO1 in WI-38 cells (35 PDs). a and d SIRT3 is localized in the mitochondria and cytoplasm of WI-38 cells. Representative confocal microscopic images of WI-38 cells are stained with anti-SIRT3 antibody (red). MitoTracker, anti-TOMM20 antibody (green), and DAPI (blue) staining were utilized for localization of mitochondria and nuclei, respectively. The images were merged for analysis of colocalization (yellow). $\mathbf{b}$ and e FOXO1 is localized in the cytoplasm and nuclei of WI-38 cells. Representative confocal microscopic images of WI-38

same time, to verify the direct effect of SIRT3 on FOXO1targeted gene expression including catalase and MnSOD, we examined the expression of target genes. The results indicated that expression levels were increased in the pSIRT3 group compared with control and vector groups (Fig. 6a and b). Together, these results indicate that the deacetylase activity of SIRT3 actually mediates FOXO1mediated transcription in mammalian cells. Meanwhile, our experimental data showed that the levels of SIRT3 deacetylase activity were greatly increased in the SIRT3 group compared with the control and vector groups (Fig. 6e).
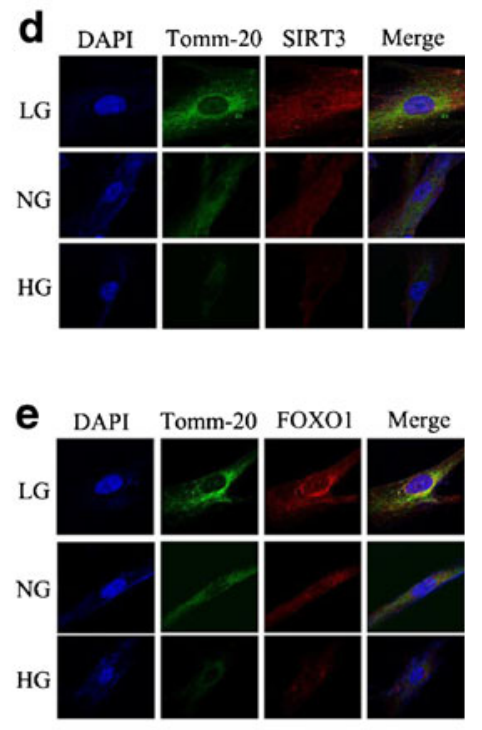

cells are stained with anti-FOXO1 antibody (red). MitoTracker, anti-TOMM20 antibody (green), and DAPI (blue) staining was utilized for localization of mitochondria and nuclei, respectively. The images were merged for analysis of colocalization (yellow). c SIRT3 colocalizes with FOXO1. Representative confocal microscopic images of WI-38 cells are stained with anti-SIRT3 antibody (red) and FOXO1 antibody (green). DAPI (blue) staining was utilized for localization of nuclei. The images were merged for analysis of colocalization (yellow). $\times 1,200$

Overexpression of SIRT3 blocks high glucose-induced premature senescence

Next, we examined whether SIRT3 overexpression can protect WI-38 cells from high glucose-induced premature senescence. As shown previously (Zhang et al. 2006), high serum glucose induces premature senescence (Figs. 1 and 2). Our results indicated that the overexpression of SIRT3 significantly reduced the number of cells positive for SA- $\beta$-gal and inhibited SAHF formation compared with empty vector (Fig. 7a, b, c and d). 
Fig. 5 SIRT3 interacts with FOXO1. Immunoprecipitation of FOXO1 (a) from lysate of WI-38 cells (35 PDs) was performed using polyclonal antibodies against FOXO1 and a control IgG. Interaction of endogenous SIRT3 and FOXO1 was detected by Western blot analysis. Immunoprecipitation from Myc-FlagFOXO1- and GFP-SIRT3transfected HEK 293 T cells (b, c, and d). Immunoprecipitations were resolved by SDS-PAGE and analyzed by immunoblotting using antibodies against FOXO1, SIRT3, GFP, Myc, and Flag. Ten percent of cell lysates (input $10 \%$ ) was used for each immunoprecipitation. $I P$ immunoprecipitation, $I B$ immunoblot analysis

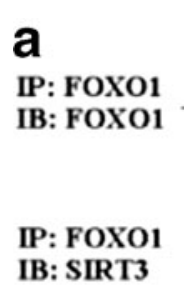

IB: FOXO1

IB: SIRT3

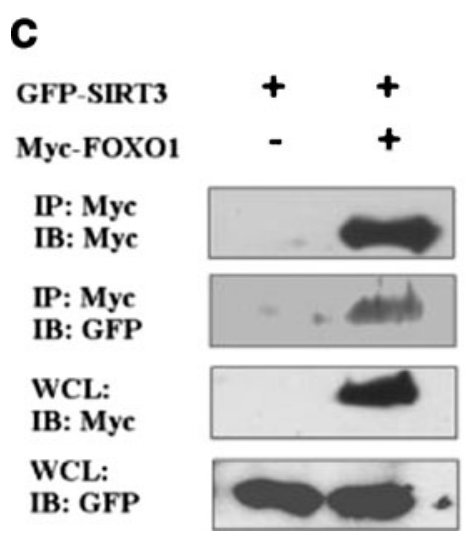

b

GFP-SIRT3

FLAG-FOXO1

IP: FLAG

IB: FLAG

IP: FLAG

IB: SIRT3

WCL:

IB: Flag

WCL:

IB: SIRT3

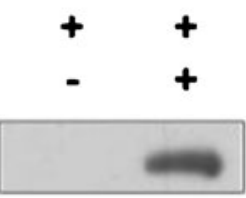

d

FLAG-FOXO1

GFP-SIRT3

IP: GFP

IB: GFP

IP: GFP

IB: Myc

WCL:

IB: GFP
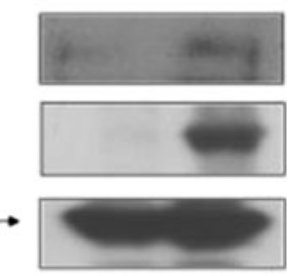

WCL:

IB: Myc

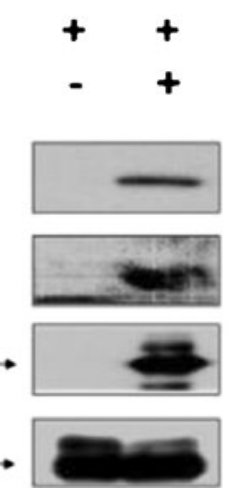

Meanwhile, the accumulation of $\mathrm{p} 16^{\mathrm{INK} 4 \mathrm{~A}}$ was decreased (Fig. 7e and f).

SIRT3 knockdown downregulates FOXO1 transactivation activity

We investigated whether inhibition of expression of SIRT3 induces cellular senescence. For this purpose, plasmid DNA sh-NC and sh-SIRT3 were stably transfected into the WI-38 cells at 20 PDs. A clone was grown to about 40 PDs under low glucose media. The results showed that inhibition of SIRT3 expression by shRNA resulted in an increase in acetylated FOXO1 (Fig. 8c and d). However, the protein expression levels of nuclear total FOXO1 of the three groups did not show a statistically significant difference. At the same time, the expressions of catalase and MnSOD in the sh-SIRT3 group was significantly lower than in the sh-NC group (Fig. 8a and b). Meanwhile, our experimental data showed that the levels of SIRT3 deacetylase activity were greatly decreased in the sh-SIRT3 group compared with the control and sh-NC

groups (Fig. 8e). These results indicated that SIRT3 knockdown can inhibit FOXO1 transactivation activity.

Inhibition of SIRT3 induces premature senescence

sh-SIRT3 and sh-NC were stably transfected into WI-38 cell at 20 PDs. At the time WI-38 cells were stained using SA- $\beta$-gal and DAPI staining when they reached 40 PDs in low glucose media. We found that SIRT3 shRNA-mediated inhibition of SIRT3 resulted in DNA foci accumulation and an increased number of cells positive for SA- $\beta$-gal (Fig. 9a, b, c, and d). Meanwhile, accumulation of $\mathrm{p} 16^{\mathrm{INK} 4 \mathrm{~A}}$ increased (Fig. 9e and f).

\section{Discussion}

Recent evidence suggests that calorie restriction, specifically, reduced glucose intake, induces extended life span in various model organisms, including Saccharomyces cerevisiae, D. melanogaster, C. elegans, and mice 


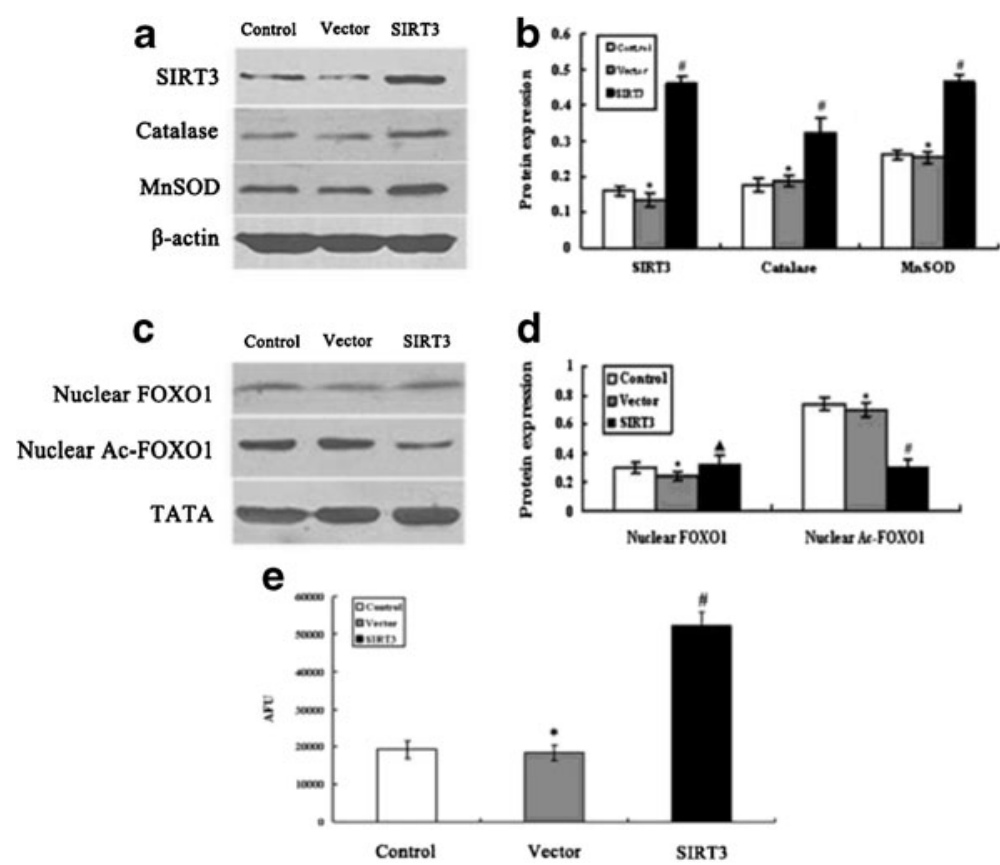

Fig. 6 SIRT3-dependent suppression of cellular senescence was through the FOXO1 pathway. a Stable transfected WI-38 cells containing pVector or pSIRT3 and an untransfected control group were lysed and prepared for Western blot analysis by using specific antibodies against SIRT3, catalase, MnSOD, and $\beta$-actin. b Expression of the proteins SIRT3, catalase, and MnSOD was compared using ANOVA. ${ }^{*} P>0.05$ vs. control group, ${ }^{\#} P<0.05$ vs. vector group. c Western blot analysis of

(Ristow and Zarse 2010; Lopez-Lluch et al. 2008; Kassi and Papavassiliou 2008; Judge and Leeuwenburgh 2007; Hunt et al. 2006; Jazwinski 2005). Meanwhile, it is well known that overexpression of Sir2 orthologs extends life span in a wide range of lower eukaryotes (Lin et al. 2000; Kenyon 2010; Rahat et al. 2011; Frankel et al. 2011). In this study, first, we found that the protein expression of SIRT3 increased under LG conditions and decreased under HG conditions in WI-38 cells. These findings inspired the assumption that SIRT3 has a role in regulating cellular senescence in WI-38 cells and is a potential pharmacological target to treat the major diseases of senescence. Second, we found that FOXO1 is acetylated by high serum glucose, and total FOXO1 expression is decreased. Third, SIRT3 binds to FOXO1 in the cytoplasm. We tried to elucidate the mechanisms of how SIRT3 and FOXO1 communicate in cellular senescence in human diploid fibroblasts.

The SIRT3 gene lies at the telomeric terminal on the 11 p15.5 chromosome (Rose et al. 2003). Schwer et nuclear FOXO1 and nuclear Ac-FOXO1 in the control group, vector group, and SIRT3 group, respectively. d Nuclear FOXO1 and nuclear Ac-FOXO1 were compared using ANOVA. ${ }^{*} P>0.05$ vs. control group, ${ }^{\boldsymbol{\Delta}} P>0.05$ vs. vector group, ${ }^{\#} P<0.05$ vs. vector group. e The deacetylase activity of SIRT3 in the control group, vector group, and SIRT3 group. ${ }^{*} P>0.05$ vs. control group, ${ }^{\#} P<0.05$ vs. vector group. Data represent three experiments with similar results

al. (2002) assayed endogenous SIRT3 in the mitochondrial fraction of human embryonic kidney cells and found that it had specific NAD-dependent deacetylase activity. Mitochondrial import of SIRT3 was dependent on an N-terminal amphipathic alpha helix rich in basic residues. A study showed that SIRT3 exists in two forms: in humans, a full-length protein of $44 \mathrm{kDa}$ and a processed polypeptide lacking 142 amino acids at its N-terminus. They discovered that SIRT3 not only localizes to the mitochondria but also to the nucleus (Scher et al. 2007). SIRT3 was proteolytically processed in the mitochondrial matrix to a $28-\mathrm{kDa}$ product, and this processing was reconstituted in vitro with recombinant mitochondrial matrix processing peptidase (MPP). Mutation analysis showed that SIRT3 was cleaved between arginines 99 and 100. The unprocessed form of SIRT3 was enzymatically inactive and became fully activated in vitro after cleavage by MPP (Schwer et al. 2002). A recent study showed that CR reduces oxidative DNA damage in multiple tissues and prevents age-related hearing 
Fig. 7 Changes of senescence-associated features in WI-38 cells were induced by enforced expression of SIRT3. a Stable transfected WI-38 cells expressing empty vector or SIRT3 and the untransfected control group under HG conditions. WI-38 cells cultured for 40 PDs were stained for SA- $\beta$-gal, which showed blue precipitation in the cytoplasm of senescent cells. b The percentage of SA$\beta$-gal stained positive cells. For each group, ${ }^{*} P>0.05$ vs. control group, ${ }^{\#} P<0.05$ vs. vector group. c Senescenceassociated heterochromatin foci (SAHF), another classical marker of senescence, were evident in WI-38 cells. DNA foci accumulate was visualized by DAPI staining in WI38 cells. d Enlarged images of DAPI staining are shown in the lower panels. e Western blot analysis of $\mathrm{p} 16^{\mathrm{INK} 4 \mathrm{~A}}$ in the three groups. f Comparison among groups was conducted using ANOVA. ${ }^{*} P>0.05$ vs. control group, ${ }^{\#} P<0.05$ vs. vector group. Data represent three experiments with similar results. $\mathbf{a} \times 100, \mathbf{c} \times 1,200, \mathbf{d} \times 3,600 \times$ a
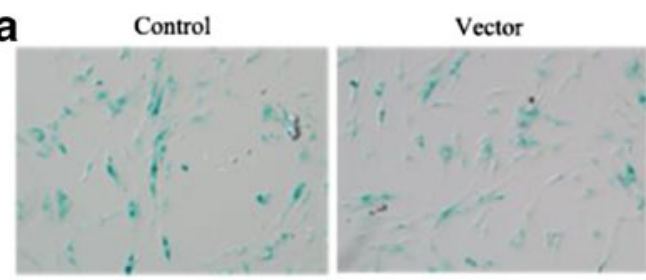

b

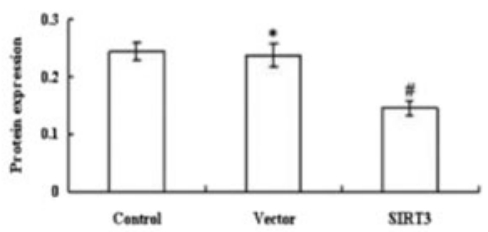

C
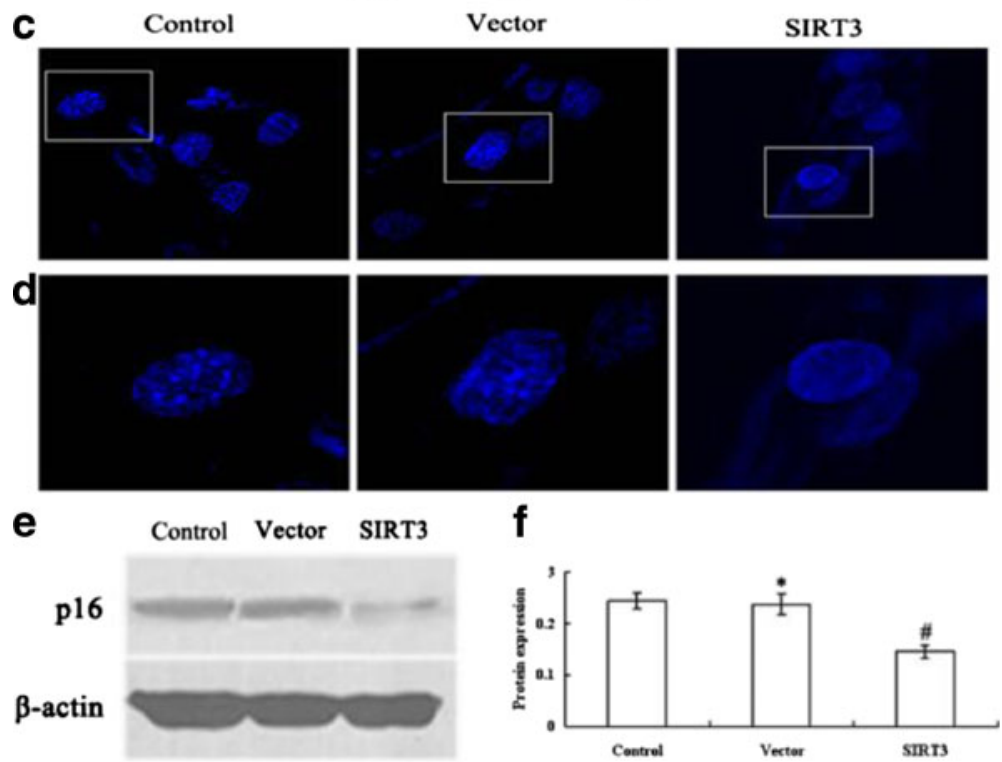

f

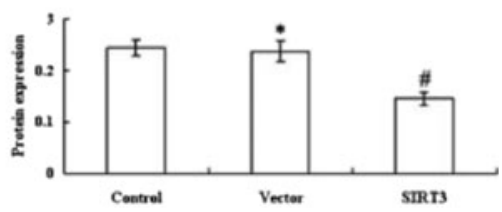

loss in wild type mice but fails to modify these phenotypes in mice lacking the mitochondrial deacetylase SIRT3 (Someya et al. 2010). Two studies demonstrated that SIRT3 deacetylates mitochondrial 3-hydroxy3-methylglutaryl CoA synthase 2, regulates ketone body production, and reduces cellular ROS levels dependent on superoxide dismutase 2 (Qiu et al. 2010; Shimazu et al.2010). We found that SIRT3 was highly expressed in the mitochondria and cytoplasm. The SIRT3 of cytoplasm came from the mitochondria in the process of cellular senescence in WI-38 cell. The SIRT3 strongly overlapped with that of FOXO1 in the cytoplasm, SIRT3 deacetylated FOXO1 and then FOXO1 from the cytoplasm into the nucleus upregulated its transcriptional activity. We observed changes in FOXO1 and Ac-FOXO1 by overexpression and suppression by the expression of SIRT3. Our results indicated that overexpression of SIRT3 results in decreased levels of nuclear Ac-FOXO1 protein, and shRNA-SIRT3 increased the expression levels of nuclear Ac-FOXO1 protein. Transcriptional activity of FOXO1 has been known to be mainly regulated by posttranslational modifications of phosphorylationdependent nuclear exclusion and deacetylationdependent nuclear retention. In spite of Sirt3 overexpression-mediated deacetylation, there is no difference in total nuclear FOXO levels in Fig. 6. Furthermore, Sirt3 shRNA was shown to increase acetylated FOXO1 without a difference in total nuclear levels (Fig. 8). These results suggest that there are different types of regulation for nuclear FOXO1 levels other than Sirt3-mediated regulation in the setting of high glucose levels. These results need to be explored in further experiments. 
a
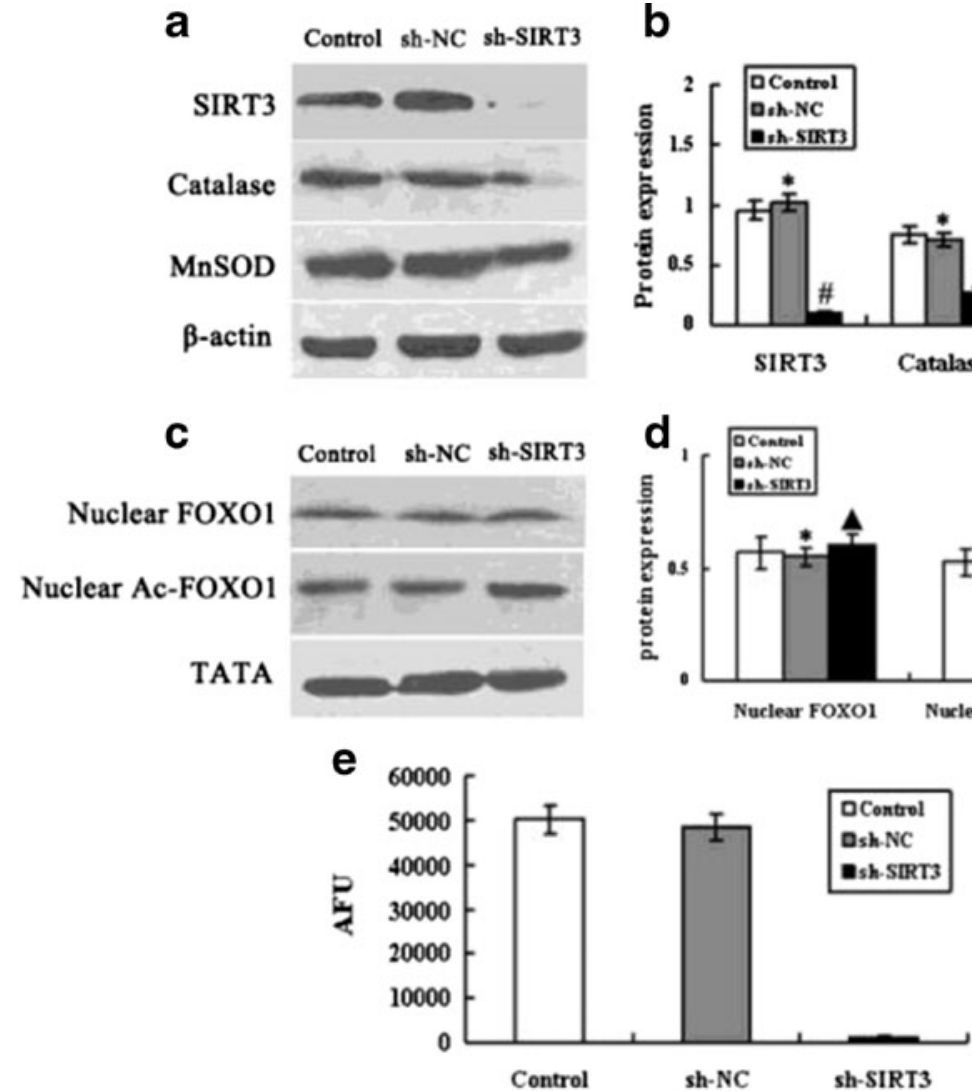

b
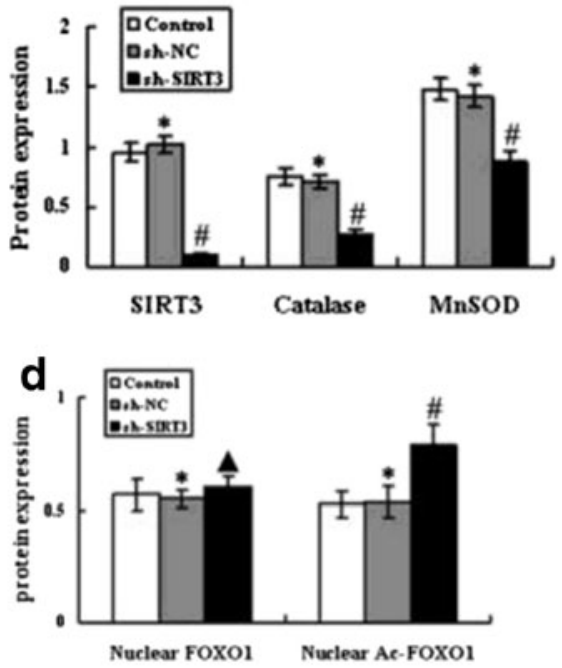

control group, sh-NC group, and sh-SIRT3 group. d Nuclear FOXO1 and nuclear Ac-FOXO1 were compared using ANOVA. ${ }^{*} P>0.05$ vs. control group, ${ }^{\wedge} P>0.05$ vs. sh-NC group, ${ }^{\#} P<0.05$ vs. sh-NC group. e The deacetylase activity of SIRT3 in the control group, sh-NC group, and sh-SIRT3 group. ${ }^{*} P>0.05$ vs. control group, ${ }^{\#} P<0.05$ vs. sh-NC group. Data represent three experiments with similar results

transcription factor, FOXO1. Deacetylation of FOXO1 by SIRT3 results in the stimulation of the expression of the FOXO target genes, catalase and MnSOD. Results from both SIRT3 overexpression and knockdown experiments suggest that FOXO deacetylation by SIRT3 activates FOXO transactivation activity. These findings are in agreement with a recent report that deacetylation of FOXO allows ubiquitination and subsequent increase of transcriptional activity of FOXO factors (Sundaresan et al. 2009).

The most important and novel finding of this study is that enforced SIRT3 expression in WI-38 cells under high glucose conditions prevented cellular premature senescence. Meanwhile, knockdown of SIRT3 by shRNA under low glucose induced cellular premature senescence. 
Fig. 9 Changes in senescence-associated features in WI-38 cells were induced by inhibited expression of SIRT3. a Stable transfected WI-38 cells expressing shRNA-NC or shRNA-SIRT3 and the untransfected control group under LG conditions. WI-38 cells cultured for 40 PDs were stained for SA- $\beta$-gal. b The percentage of SA- $\beta$ gal-stained positive cells. For each group, ${ }^{*} P>0.05$ vs. control group, ${ }^{\#} P<0.05$ vs. shRNA-NC group. c Analysis of SAHF formation shown in WI-38 cells. DNA foci accumulation was visualized by DAPI staining in WI-38 cells. d Enlarged images of DAPI staining are shown in the lower panels. $\mathrm{e}$ Western blot analysis of p $16^{\text {INK4A }}$ in the three groups. f Comparison among groups was conducted using ANOVA. ${ }^{*} P>0.05$ vs. control group, ${ }^{\#} P<0.05$ vs. sh-NC group. Data represent three experiments with similar results. $\mathbf{a} \times 100, \mathbf{c} \times 1,200, \mathbf{d} \times 3,600$ a

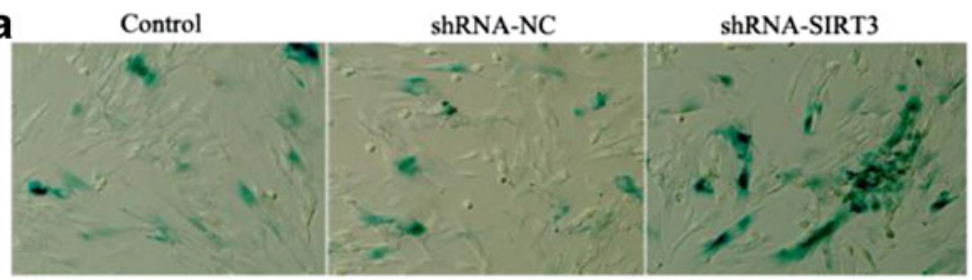

b
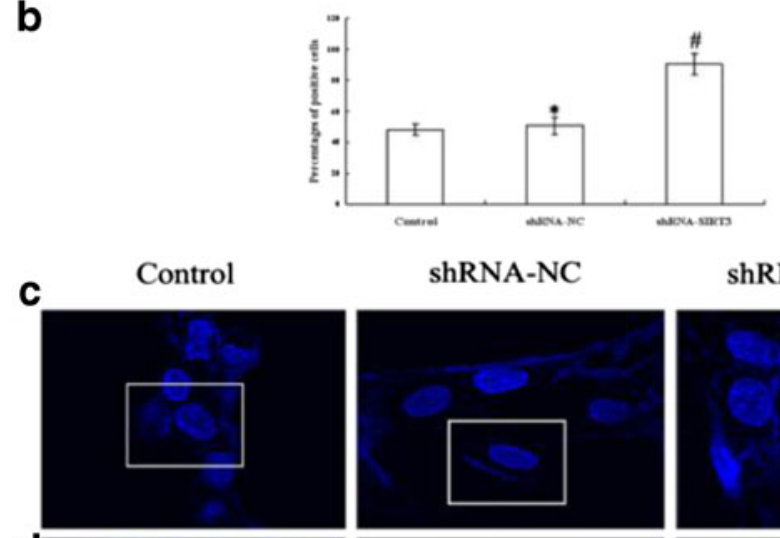

ShRNA-SIRT3
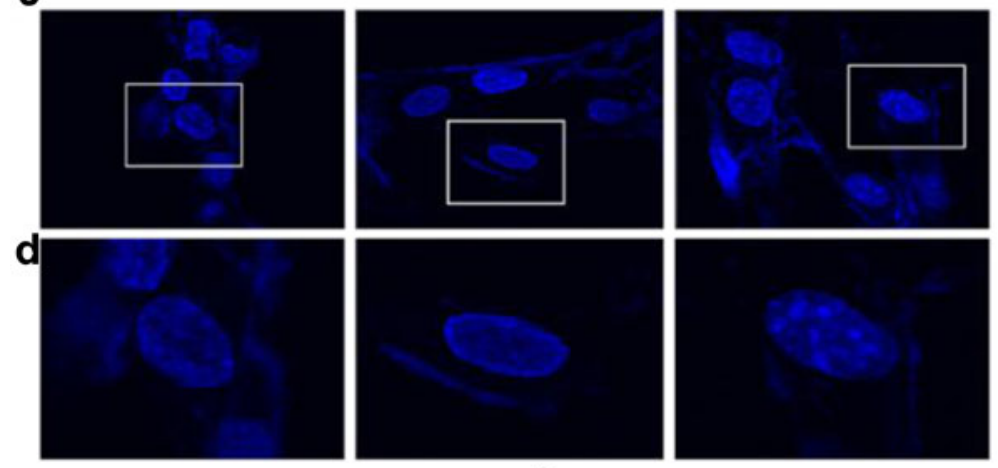

e

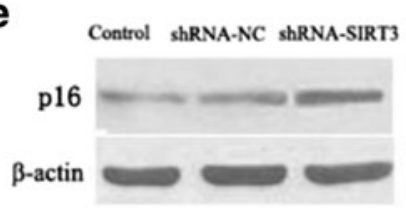

f

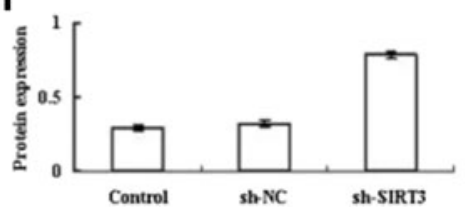

Caloric restriction is the only well-characterized condition that can extend the life span in organisms ranging from yeast to mammals (Kenyon 2010). Li et al. found that glucose restriction (GR) can inhibit cellular senescence and significantly extend cellular life span compared with cells receiving normal glucose (NG) in the culture medium (Li and Tollefsbol 2011). Previously, many studies have demonstrated that CR increases the expression of SIRT1 and that the life span extension associated with CR is dependent on SIRT1 expression (Canto and Auwerx 2009; Saunders and Verdin 2009; Gillum et al. 2010). Meanwhile, many studies found that FOXO gene variants have also been linked to longevity in several cohorts. It is striking that FOXO variants are consistently associated with longevity (Anselmi et al. 2009; Flachsbart et al. 2009; Li et al. 2009; Lunetta et al. 2007; Willcox et al. 2008).

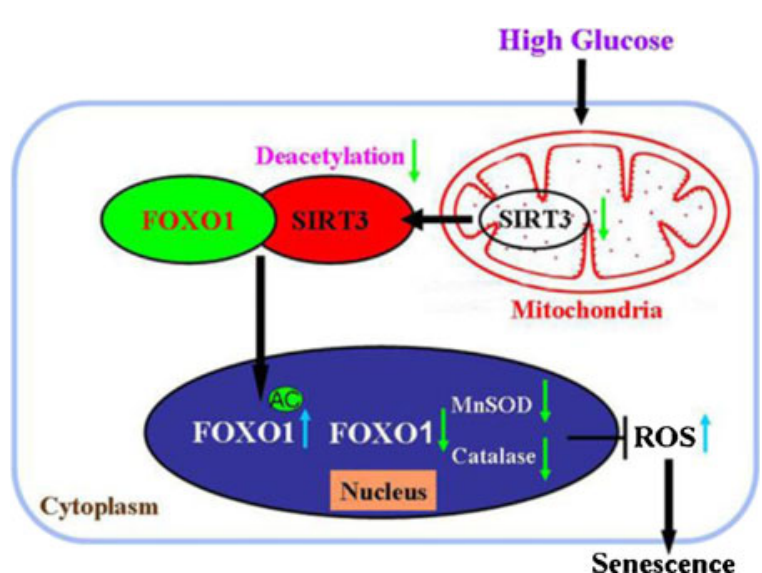

Fig. 10 Schematic model for a mechanism of SIRT3 overexpression antagonizes high glucose accelerated cellular senescence in human diploid fibroblasts via the SIRT3-FOXO1 signaling pathway 
This model indicated SIRT3 may pose a central role in cellular senescence through directly modulating FOXO1 signaling under the circumstance of high glucose (Fig. 10). In summary, our data, for the first time, suggested roles of SIRT3 and FOXO1 in the relationship with cellular premature senescence in human diploid fibroblasts: SIRT3 overexpression antagonizes high glucose-accelerated cellular senescence in human diploid fibroblasts via the SIRT3-FOXO1 signaling pathway.

Acknowledgments We thank Chi-Dug Kang for the gift of pCMV6-AC-GFP vector. This work was supported by the National Basic Research program of China (973 Program) (2007CB507400), and a grant from the National Natural Science Foundation of China $(30771014,81070267)$.

Open Access This article is distributed under the terms of the Creative Commons Attribution License which permits any use, distribution, and reproduction in any medium, provided the original author(s) and the source are credited.

\section{References}

Ahn BH, Kim HS, Song S, Lee IH, Liu J, Vassilopoulos A, Deng CX, Finkel T (2008) A role for the mitochondrial deacetylase Sirt3 in regulating energy homeostasis. Proc Natl Acad Sci USA 105(38):14447-14452. doi:10.1073/ pnas.0803790105

Anselmi CV, Malovini A, Roncarati R, Novelli V, Villa F, Condorelli G, Bellazzi R, Puca AA (2009) Association of the FOXO3A locus with extreme longevity in a southern Italian centenarian study. Rejuvenation Res 12(2):95-104. doi:10.1089/rej.2008.0827

Bao J, Scott I, Lu Z, Pang L, Dimond CC, Gius D, Sack MN (2010) SIRT3 is regulated by nutrient excess and modulates hepatic susceptibility to lipotoxicity. Free Radic Biol Med 49 (7):1230-1237. doi:10.1016/j.freeradbiomed.2010.07.009

Bellizzi D, Rose G, Cavalcante P, Covello G, Dato S, De Rango F, Greco V, Maggiolini M, Feraco E, Mari V, Franceschi C, Passarino G, De Benedictis G (2005) A novel VNTR enhancer within the SIRT3 gene, a human homologue of SIR2, is associated with survival at oldest ages. Genomics 85(2):258-263. doi:10.1016/j.ygeno.2004.11.003

Benigni A, Corna D, Zoja C, Sonzogni A, Latini R, Salio M, Conti S, Rottoli D, Longaretti L, Cassis P, Morigi M, Coffman TM, Remuzzi G (2009) Disruption of the Ang II type 1 receptor promotes longevity in mice. J Clin Invest 119(3):524-530. doi:10.1172/JCI36703

Borradaile NM, Pickering JG (2009) Nicotinamide phosphoribosyltransferase imparts human endothelial cells with extended replicative lifespan and enhanced angiogenic capacity in a high glucose environment. Aging Cell 8(2):100-112. doi:10.1111/j.1474-9726.2009.00453.x

Brunet A, Sweeney LB, Sturgill JF, Chua KF, Greer PL, Lin Y, Tran H, Ross SE, Mostoslavsky R, Cohen HY, Hu LS, Cheng
HL, Jedrychowski MP, Gygi SP, Sinclair DA, Alt FW, Greenberg ME (2004) Stress-dependent regulation of FOXO transcription factors by the SIRT1 deacetylase. Science 303 (5666):2011-2015. doi:10.1126/science.1094637

Canto C, Auwerx J (2009) Caloric restriction, SIRT1 and longevity. Trends Endocrinol Metab 20(7):325-331. doi:10.1016/j.tem.2009.03.008

Daitoku H, Hatta M, Matsuzaki H, Aratani S, Ohshima T, Miyagishi M, Nakajima T, Fukamizu A (2004) Silent information regulator 2 potentiates Foxo1-mediated transcription through its deacetylase activity. Proc Natl Acad Sci USA 101 (27):10042-10047. doi:10.1073/pnas.0400593101

de Oliveira RM, Pais TF, Outeiro TF (2010) Sirtuins: common targets in aging and in neurodegeneration. Curr Drug Targets 11(10):1270-1280, doi:BSP/CDT/E-Pub/00134

Dimri GP, Lee X, Basile G, Acosta M, Scott G, Roskelley C, Medrano EE, Linskens M, Rubelj I, Pereira-Smith O et al (1995) A biomarker that identifies senescent human cells in culture and in aging skin in vivo. Proc Natl Acad Sci USA 92(20):9363-9367

Duan J, Zhang Z, Tong T (2001) Senescence delay of human diploid fibroblast induced by anti-sense p16INK4a expression. J Biol Chem 276(51):48325-48331. doi:10.1074/ jbc.M104814200

Flachsbart F, Caliebe A, Kleindorp R, Blanche H, von EllerEberstein H, Nikolaus S, Schreiber S, Nebel A (2009) Association of FOXO3A variation with human longevity confirmed in German centenarians. Proc Natl Acad Sci USA 106(8):2700-2705. doi:10.1073/pnas.0809594106

Frankel S, Ziafazeli T, Rogina B (2011) dSir2 and longevity in Drosophila. Exp Gerontol 46(5):391-396. doi:10.1016/ j.exger.2010.08.007

Frescas D, Valenti L, Accili D (2005) Nuclear trapping of the forkhead transcription factor FoxO1 via Sirt-dependent deacetylation promotes expression of glucogenetic genes. J Biol Chem 280(21):20589-20595. doi:10.1074/ jbc.M412357200

Furukawa-Hibi Y, Kobayashi Y, Chen C, Motoyama N (2005) FOXO transcription factors in cell-cycle regulation and the response to oxidative stress. Antioxid Redox Signal 7(56):752-760. doi:10.1089/ars.2005.7.752

Giannakou ME, Goss M, Partridge L (2008) Role of dFOXO in lifespan extension by dietary restriction in Drosophila melanogaster: not required, but its activity modulates the response. Aging Cell 7(2):187-198. doi:10.1111/j.14749726.2007.00362.x

Gillum MP, Erion DM, Shulman GI (2010) Sirtuin-1 regulation of mammalian metabolism. Trends Mol Med. doi:S14714914(10)00140-1 [pii] 10.1016/j.molmed.2010.09.005

Haigis MC, Guarente LP (2006) Mammalian sirtuins - emerging roles in physiology, aging, and calorie restriction. Genes Dev 20(21):2913-2921. doi:10.1101/gad.1467506

Huang H, Tindall DJ (2007) Dynamic FoxO transcription factors. J Cell Sci 120(Pt 15):2479-2487. doi:10.1242/jcs.001222

Hunt ND, Hyun DH, Allard JS, Minor RK, Mattson MP, Ingram DK, de Cabo R (2006) Bioenergetics of aging and calorie restriction. Ageing Res Rev 5(2):125-143. doi:10.1016/ j.arr.2006.03.006

Jazwinski SM (2005) Yeast longevity and aging - the mitochondrial connection. Mech Ageing Dev 126(2):243-248. doi:10.1016/j.mad.2004.08.016 
Judge S, Leeuwenburgh C (2007) Cardiac mitochondrial bioenergetics, oxidative stress, and aging. Am J Physiol Cell Physiol 292(6):C1983-1992. doi:10.1152/ajpcell.00285.2006

Kassi E, Papavassiliou AG (2008) Could glucose be a proaging factor? J Cell Mol Med 12(4):1194-1198. doi:10.1111/ j.1582-4934.2008.00329.x

Kenyon CJ (2010) The genetics of ageing. Nature 464 (7288):504-512. doi:10.1038/nature08980

Kitamura YI, Kitamura T, Kruse JP, Raum JC, Stein R, Gu W, Accili D (2005) FoxO1 protects against pancreatic beta cell failure through NeuroD and MafA induction. Cell Metab 2 (3):153-163. doi:10.1016/j.cmet.2005.08.004

Kong X, Wang R, Xue Y, Liu X, Zhang H, Chen Y, Fang F, Chang Y, Deb S (2010) Sirtuin 3, a new target of PGC-1 $\alpha$, plays an important role in the suppression of ROS and mitochondrial biogenesis. PLoS One 5(7):e11707. doi:10.1371/journal.pone.0011707

Lanza IR, Short DK, Short KR, Raghavakaimal S, Basu R, Joyner MJ, McConnell JP, Nair KS (2008) Endurance exercise as a countermeasure for aging. Diabetes 57 (11):2933-2942. doi:10.2337/db08-0349

Lauri SE, Delany C, VR JC, Bortolotto ZA, Ornstein PL JTRI, Collingridge GL (2001) Synaptic activation of a presynaptic kainate receptor facilitates AMPA receptor-mediated synaptic transmission at hippocampal mossy fibre synapses. Neuropharmacology 41(8):907-915

Li Y, Tollefsbol TO (2011) p16(INK4a) suppression by glucose restriction contributes to human cellular lifespan extension through SIRT1-mediated epigenetic and genetic mechanisms. PLoS One 6(2):e17421. doi:10.1371/journal.pone.0017421

Li Y, Wang WJ, Cao H, Lu J, Wu C, Hu FY, Guo J, Zhao L, Yang F, Zhang YX, Li W, Zheng GY, Cui H, Chen X, Zhu Z, He H, Dong B, Mo X, Zeng Y, Tian X (2009) Genetic association of FOXO1A and FOXO3A with longevity trait in Han Chinese populations. Hum Mol Genet 18 (24):4897-4904. doi:10.1093/hmg/ddp459

Lin SJ, Defossez PA, Guarente L (2000) Requirement of NAD and SIR2 for life-span extension by calorie restriction in Saccharomyces cerevisiae. Science 289(5487):2126-2128, doi:8813

Liu W, Hong Q, Bai XY, Fu B, Xie Y, Zhang X, Li J, Shi S, Lv Y, Sun X, Chen X (2010) High-affinity $\mathrm{Na}(+)$-dependent dicarboxylate cotransporter promotes cellular senescence by inhibiting SIRT1. Mech Ageing Dev 131(10):601613. doi:10.1016/j.mad.2010.08.006

Lopez-Lluch G, Irusta PM, Navas P, de Cabo R (2008) Mitochondrial biogenesis and healthy aging. Exp Gerontol 43 (9):813-819. doi:10.1016/j.exger.2008.06.014

Lunetta KL, D'Agostino RB Sr, Karasik D, Benjamin EJ, Guo CY, Govindaraju R, Kiel DP, Kelly-Hayes M, Massaro JM, Pencina MJ, Seshadri S, Murabito JM (2007) Genetic correlates of longevity and selected age-related phenotypes: a genome-wide association study in the Framingham Study. BMC Med Genet 8(Suppl 1):S13. doi:10.1186/1471-2350-8$\mathrm{S} 1-\mathrm{S} 13$

Murphy CT (2006) The search for DAF-16/FOXO transcriptional targets: approaches and discoveries. Exp Gerontol 41 (10):910-921. doi:10.1016/j.exger.2006.06.040

Narita M, Nunez S, Heard E, Lin AW, Hearn SA, Spector DL, Hannon GJ, Lowe SW (2003) Rb-mediated heterochromatin formation and silencing of E2F target genes during cellular senescence. Cell 113(6):703-716
Onyango P, Celic I, McCaffery JM, Boeke JD, Feinberg AP (2002) SIRT3, a human SIR2 homologue, is an NADdependent deacetylase localized to mitochondria. Proc Natl Acad Sci USA 99(21):13653-13658. doi:10.1073/ pnas.222538099

Qiu X, Brown K, Hirschey MD, Verdin E, Chen D (2010) Calorie restriction reduces oxidative stress by SIRT3mediated SOD2 activation. Cell Metab 12(6):662-667. doi:10.1016/j.cmet.2010.11.015

Rahat O, Maoz N, Cohen HY (2011) Multiple pathways regulating the calorie restriction response in yeast. J Gerontol A Biol Sci Med Sci 66(2):163-169. doi:10.1093/gerona/glq165

Ristow M, Zarse K (2010) How increased oxidative stress promotes longevity and metabolic health: the concept of mitochondrial hormesis (mitohormesis). Exp Gerontol 45 (6):410-418. doi:10.1016/j.exger.2010.03.014

Rose G, Dato S, Altomare K, Bellizzi D, Garasto S, Greco V, Passarino G, Feraco E, Mari V, Barbi C, BonaFe M, Franceschi C, Tan Q, Boiko S, Yashin AI, De Benedictis G (2003) Variability of the SIRT3 gene, human silent information regulator Sir2 homologue, and survivorship in the elderly. Exp Gerontol 38(10):1065-1070

Saunders LR, Verdin E (2009) Cell biology. Stress response and aging. Science 323(5917):1021-1022. doi:10.1126/ science. 1170007

Scher MB, Vaquero A, Reinberg D (2007) SirT3 is a nuclear NAD+-dependent histone deacetylase that translocates to the mitochondria upon cellular stress. Genes Dev 21 (8):920-928. doi:10.1101/gad.1527307

Schwer B, North BJ, Frye RA, Ott M, Verdin E (2002) The human silent information regulator $(\mathrm{Sir}) 2$ homologue hSIRT3 is a mitochondrial nicotinamide adenine dinucleotide-dependent deacetylase. J Cell Biol 158 (4):647-657. doi:10.1083/jcb.200205057

Sedding DG (2008) FoxO transcription factors in oxidative stress response and ageing - a new fork on the way to longevity? Biol Chem 389(3):279-283. doi:10.1515/ BC.2008.033

Shi T, Wang F, Stieren E, Tong Q (2005) SIRT3, a mitochondrial sirtuin deacetylase, regulates mitochondrial function and thermogenesis in brown adipocytes. J Biol Chem 280 (14):13560-13567. doi:10.1074/jbc.M414670200

Shimazu T, Hirschey MD, Hua L, Dittenhafer-Reed KE, Schwer B, Lombard DB, Li Y, Bunkenborg J, Alt FW, Denu JM, Jacobson MP, Verdin E (2010) SIRT3 deacetylates mitochondrial 3-hydroxy-3-methylglutaryl CoA synthase 2 and regulates ketone body production. Cell Metab 12(6):654661. doi:10.1016/j.cmet.2010.11.003

Someya S, Yu W, Hallows WC, Xu J, Vann JM, Leeuwenburgh C, Tanokura M, Denu JM, Prolla TA (2010) Sirt3 mediates reduction of oxidative damage and prevention of agerelated hearing loss under caloric restriction. Cell 143 (5):802-812. doi:10.1016/j.cell.2010.10.002

Sundaresan NR, Gupta M, Kim G, Rajamohan SB, Isbatan A, Gupta MP (2009) Sirt3 blocks the cardiac hypertrophic response by augmenting Foxo3a-dependent antioxidant defense mechanisms in mice. J Clin Invest 119(9):27582771. doi:10.1172/JCI39162

Willcox BJ, Donlon TA, He Q, Chen R, Grove JS, Yano K, Masaki KH, Willcox DC, Rodriguez B, Curb JD (2008) FOXO3A genotype is strongly associated with human 
longevity. Proc Natl Acad Sci USA 105(37):13987-13992, 10.1073/pnas.0801030105

Yamaza H, Komatsu T, Wakita S, Kijogi C, Park S, Hayashi H, Chiba T, Mori R, Furuyama T, Mori N, Shimokawa I (2010) FoxO1 is involved in the antineoplastic effect of calorie restriction. Aging Cell 9((3):372-382. doi:10.1111/j.14749726.2010.00563.x

Yang Y, Cimen H, Han MJ, Shi T, Deng JH, Koc H, Palacios OM, Montier L, Bai Y, Tong Q, Koc EC (2010) NAD+dependent deacetylase SIRT3 regulates mitochondrial protein synthesis by deacetylation of the ribosomal protein MRPL10. J Biol Chem 285(10):7417-7429, 10.1074/ jbc.M109.053421
Zanella F, Link W, Carnero A (2010) Understanding FOXO, new views on old transcription factors. Curr Cancer Drug Targets 10 (2):135-146. doi:EPub-Abstract-CCDT-02 [pii] Zhang X, Chen X, Wu D, Liu W, Wang J, Feng Z, Cai G, Fu B, Hong Q, Du J (2006) Downregulation of connexin 43 expression by high glucose induces senescence in glomerular mesangial cells. J Am Soc Nephrol 17(6):1532-1542. doi:10.1681/ASN.2005070776

Zhuo L, Cai G, Liu F, Fu B, Liu W, Hong Q, Ma Q, Peng Y, Wang J, Chen X (2009) Expression and mechanism of mammalian target of rapamycin in age-related renal cell senescence and organ aging. Mech Ageing Dev 130(10):700-708. doi:10.1016/j.mad.2009.08.005 